\section{Time-out as a determinant of rate of response and rate of avoidance*}

\author{
HARRY M. B. HURWITZ and A. E. ROBERTS† \\ University of Guelph, Guelph, Ont., Canada
}

Two rats were trained under a free operant avoidance procedure. Introduction of a time-out period resulted in an increase in response rate, a reduction in shock rate, and an increase in the probability of shock at the commencement of each time-in. The effect was most pronounced with a time-out of $1 \mathrm{~min}$ and least with $16 \mathrm{sec}$. An explanation in terms of the effect of time-out on relaxing responses and the heightened sensitivity of shock is proposed.
Following extensive training in an avoidance situation, Ss will successfully prevent most, but not all, of the avoidable stimuli during an experimental session. Furthermore, it is generally observed that noxious stimuli are avoided less frequently at the beginning of each session than later. This finding has been documented and investigated under discriminated avoidance schedules where a signal is presented to indicate the time period available for performing the required response (Hoffman, Fleschler, \& Chorny, 1961; Hoffman \& Fleschler, 1962; Nakamura \& Anderson, 1962). It has also been observed and noted under a nondiscriminated free operant avoidance schedule (e.g., Wertheim, $1965)$ and has been termed the "warm-up effect" (Hoffman, 1965). If a few unavoidable and inescapable shocks are given immediately before the shock-avoidance schedule is begun, the warm-up effect is greatly reduced. This has led some writers to claim that the effect is due to an insufficient level of anxiety at the beginning of a session. Kamin's (1956) finding that a $1-h$ intersession interval produced less decrement in avoidance than a 24-h interval lends additional support to the anxiety arousal hypothesis of the warm-up effect.

The present study focused on smaller intervals between avoidance sessions than those used in earlier research. Specifically, we investigated the effect of dividing an individual session into time-in periods of constant length (1 $\mathrm{min})$ and time-out periods which varied between 16 and 120 sec. Each $S$ was given extensive training under each time-out interval selected. The primary measure used was the probability of avoiding the first shock at the commencement of

*Supported by Grant GB-8505 from NSF to Dr. Harry M. B. Hurwitz, University of Tennessee. Reprints may be obtained from Dr. H. M. B. Hurwitz, Department of Psychology, University of Guelph, Guelph, Ontario, Canada. North Carolina.
+Now at Catawba College, Salisbury, each time-in period, but rates of response in the time-in and time-out periods were also examined.

One would predict, on the anxiety arousal hypothesis, that as time-out increased, the probability of the $S$ receiving the first shock in each time-in period would also increase. The effect on rate of response and on rate of shock are less readily predictable.

\section{SUBJECTS}

Two female hooded rats, approximately 180 days old at the beginning of experimentation, served as Ss. The rats were supplied by Spruce Farms, N.J.

\section{APPARATUS}

A Lehigh Valley operant conditioning chamber was equipped with stainless steel grids spaced $2 \mathrm{~cm}$ apart. A $4.7-\mathrm{cm}$-wide lever protruded $2.3 \mathrm{~cm}$ into the chamber, $0.5 \mathrm{~cm}$ above grid level, and responded to a pressure of $0.9 \mathrm{~N}$ by closing a microswitch. The output of a constant-current shock source, delivering $0.8 \mathrm{~mA}$, was fed through a relay scrambling device onto the grids.

The leverpressing chamber was housed inside a sound-insulated cubicle which was placed, along with other experimental chambers, into a man-sized sound-attenuated cubicle in the main area of the operant laboratory. Relay programming equipment and recording counters were outside the cubicle. \section{PROCEDURE}

Both Ss were trained to avoid shock under a free operant avoidance schedule in which 0.3 -sec inescapable shocks were presented at 5-sec intervals (the shock-shock interval). A leverpressing response postponed shock for 20 sec (the response-shock interval). Twenty $2 \cdot h$ training sessions were given in which each response also resulted in the brief offset of the houselights; nine subsequent $2 \cdot \mathrm{h}$ sessions were given under the same schedule conditions, but the houselights were permanently displayed and were not affected by the S's responses.

The second phase of training involved a change in the temporal intervals: both the shock-shock and the response-shock intervals were set at $4.5 \mathrm{sec}$. The houselights were turned on at the beginning of each session and were not affected by responses. Twenty-three 1 -h sessions were given under this training phase.

The procedure was then changed so that periods in which the avoidance schedule was in effect (time-in) alternated with periods during which the avoidance schedule was suspended (time-out). Time-in (TI) was always $1 \mathrm{~min}$, but the duration of time-out (TO) was varied over blocks of sessions: $16,30,60$, and 120 sec. TO was indicated by the offset of houselights, whereas the houselights remained on during the TI periods. Table 1 presents the order in which TO phases were given and the number of sessions under each phase. The experiment terminated after 109 sessions (days).

The number of responses emitted in TO and TI periods were recorded; in addition to the total number of shocks received during $\mathrm{TI}$ periods, the number of shocks occurring within 5 sec of the commencement of each TI period were separately obtained.

\section{RESULTS}

Table 2 shows mean responses per minute and shocks per minute for Rats $B$ and $C$ over the final five training sessions, during which every response produced a brief offset of the houselights, the final five sessions in which each response was unaccompanied by a feedback stimulus, and the final five sessions
Table 1

Summary of Procedures

\begin{tabular}{|c|c|c|}
\hline Phase & Time-Out Value & $\begin{array}{c}\text { Sessions } \\
\text { (Days) }\end{array}$ \\
\hline 1 & No $\mathrm{TO} ; \mathrm{R}-\mathrm{S}=20 \mathrm{Sec}$ & 29 \\
\hline 2 & No $T O ; R-S=4.5 \mathrm{Sec}$ & 23 \\
\hline 3 & $\mathrm{TO}=30 \mathrm{Sec} ; \mathrm{R}-\mathrm{S}=4.5 \mathrm{Sec}$ & 4 \\
\hline 4 & TO $=120 \mathrm{Sec} ; \mathrm{R}-\mathrm{S}=4.5 \mathrm{Sec}$ & 4 \\
\hline 5 & TO $=30$ Sec $; R-S=4.5$ Sec & 4 \\
\hline 6 & $\mathrm{TO}=16 \mathrm{Sec} ; \mathrm{R}-\mathrm{S}=4.5 \mathrm{Sec}$ & 15 \\
\hline 7 & $\mathrm{TO}=30 \mathrm{Sec} ; \mathrm{R}-\mathrm{S}=4.5 \mathrm{Sec}$ & 10 \\
\hline 8 & $\mathrm{TO}=60 \mathrm{Sec} ; \mathrm{R}-\mathrm{S}=4.5 \mathrm{Sec}$ & 10 \\
\hline 9 & $\mathrm{TO}=120 \mathrm{Sec} ; \mathrm{R}-\mathrm{S}=4.5 \mathrm{Sec}$ & 10 \\
\hline
\end{tabular}


Table 2

Rate of Response Per $M$ inute and Rate of Shock Per Minute When the Response-Shock Interval was 20 Sec (With and Without Feedback) and 4.5 Sec

\begin{tabular}{|c|c|c|c|c|}
\hline \multirow[b]{2}{*}{ Procedure } & \multicolumn{2}{|c|}{$\mathbf{S}_{\mathbf{B}}$} & \multicolumn{2}{|c|}{$\mathrm{s}_{\mathrm{C}}$} \\
\hline & $\begin{array}{c}\text { Response } \\
\text { Rate }\end{array}$ & $\begin{array}{c}\text { Shock } \\
\text { Rate }\end{array}$ & $\begin{array}{c}\text { Response } \\
\text { Rate }\end{array}$ & $\begin{array}{c}\text { Shock } \\
\text { Rate }\end{array}$ \\
\hline $\begin{array}{l}R-S=20 \text { Sec } ; \text { Feedback } \\
R-S=20 \text { Sec } ; \text { No Feedback } \\
R-S=4.5 \text { Sec } ; \text { No Feedback }\end{array}$ & $\begin{array}{r}9.32 \\
10.07 \\
32.72\end{array}$ & $\begin{array}{r}.34 \\
.34 \\
1.42\end{array}$ & $\begin{array}{r}8.90 \\
9.95 \\
23.77\end{array}$ & $\begin{array}{r}.34 \\
.62 \\
3.89\end{array}$ \\
\hline
\end{tabular}

having a response-shock interval of $4.5 \mathrm{sec}$.

The rate of response and the rate of shock were comparable for the two Ss over the initial training sessions in which the response-shock interval was 20 sec. Although withdrawing the response-feedback resulted in Rat C's receiving double the number of shocks, the rates of response were not noticeably affected.

Reducing the response-shock interval from 20 to $4.5 \mathrm{sec}$ had a substantial effect: both $S$ increased their rate of response threefold, whereas the rate of shock increased four- to sixfold.

The initial effect produced by the TO procedure is not presented here because we were interested in studying behavior under stable conditions rather than the acquisition function. Before the first 16-sec TO interval was

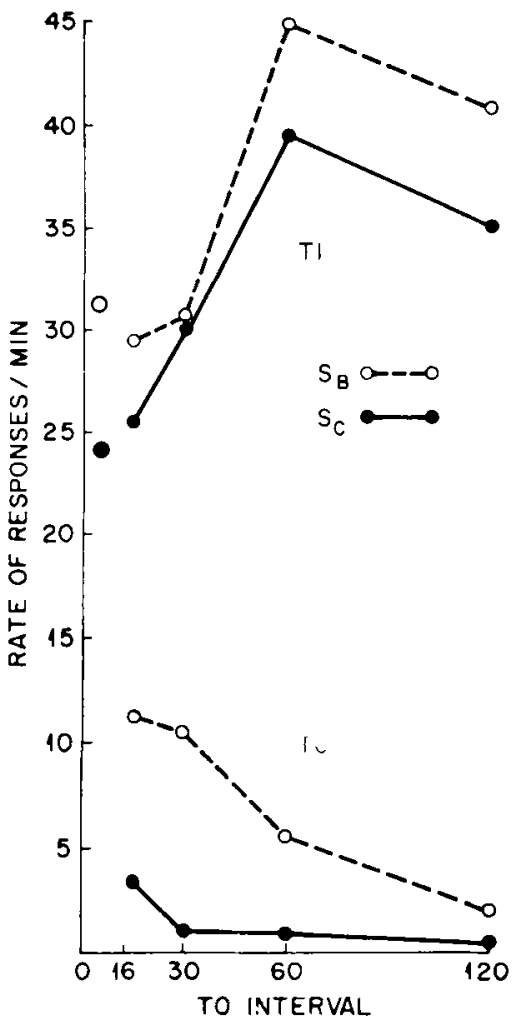

Fig. 1. Rate of response for two Ss during avoidance (TI) and time out as a function of the duration of the time-out (TO) interval. introduced, the Ss had been exposed to TOs of 30 and 120 sec (Fig. 1; see Table,1). The results of the final five sessions under the 16-, 30-,60-, and 120 -sec TO, in terms of the response rate during $\mathrm{TO}$ and $\mathrm{TI}$ periods, are given in Fig. 1. Figure 2 presents data on the rate of shock, and Fig. 3 indicates the percent of shock received in the first 5 sec of the TI periods as a function of the duration of TO.

As the TO period was increased, the rate of response in TI showed a sharp increase to a point at which $\mathrm{TO}=60 \mathrm{sec} ;$ thereafter, a slight decrease in TI rate was observed. Stimulus control was established during early sessions shortly after the TO-TI procedure was introduced. The rate of response during the TI increased as the rate in TO decreased. A sharp difference in response rate between $T O$ and TI occurred even at the lowest TO interval, $16 \mathrm{sec}$, which supports the conclusion that stimulus control was present in all the conditions studied.

The shock rates are plotted as a function of the TO values in Fig. 2. Although rates of shock were different for each of the two Ss, the function has a similar form. In general, introduction of the TO procedure reduced rate of shock: shock rates were lowest when $\mathrm{TO}=30 \mathrm{sec}$ and were highest when $\mathrm{TO}=60$ sec.

Figure 3 presents the probability of the $S$ receiving a shock during the first $5 \mathrm{sec}$ of the TI period. For both Ss, the probability of shock increased as . function of the TO duration: the probability of receiving shock at the beginning of each TI period increased although the over-all rate of shock decreased as a function of TO duration.

\section{DISCUSSION}

After extensive training in a continuous avoidance situation, two rats were exposed to a procedure in which the period in the avoidance schedule (TI) alternated with periods of TO. TI and TO were signaled. TI was always $1 \mathrm{~min}$ in duration, whereas the duration of TO was varied over blocks of sessions and ranged from 16 to $120 \mathrm{sec}$. Introducing $\mathrm{TO}$ resulted in a substantial effect: rate of response increased during $T I$ and decreased during TO. An analysis of response rate indicated that the rate of response

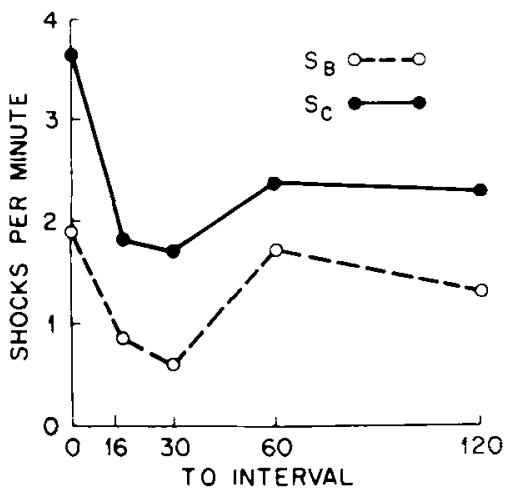

Fig. 2. Rate of shock as a function of the duration of the time-out (TO) interval.

during TI was controlled by the duration of TO: increases in TO duration resulted in an increased response rate during TI. One consequence of such increased responding under the avoidance schedule was a reduction in the number of shocks delivered. However, it was shown that the probability of obtaining the first shock during each TI period increased as the duration of TO was increased.

We have interpreted our results by reference to two well-established notions:

(1) First is the notion that an avoidance situation is stressful, arouses anxiety and results in anxiety-elicited responses (Mowrer, 1939; Denny, 1971). Anxiety is increased the more often shock is encountered. A period of respite from the anxiety situation, i.e., a period of TO immediately following $T I$, would result in the reduction of stress, a diminution of anxiety-elicited responses and an increase in those responses which typically are incompatible to those made during the TI period. Denny has suggested that the motor responses performed during TO periods are those

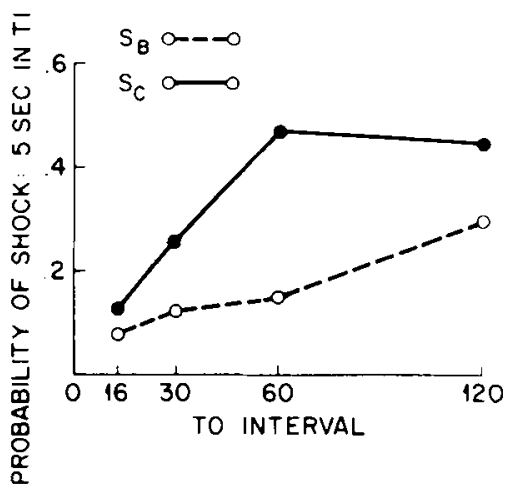

Fig. 3. Probability of shock during the first 5 sec during each period under the avoidance schedule as a function of the duration of the time-out (TO) interval. 
of relaxation and that such responses are highly correlated with distinctive autonomic reactions. Thus, after active avoidance training, Ss become passive whenever the avoidance schedule is suspended.

(2) The second notion is that prolonged TO increases the S's sensitivity to shock, i.e., the longer the $S$ is removed from the aversive and noxious stimuli, the greater would be the impact made when such stimuli are subsequently encountered. This conclusion is consonant with the finding that the effect of shock is not only attributable to its physical characteristics, but depends to a larger degree on its schedule of presentation. In this respect, the notion is in harmony with recent work on behavioral contrast which shows that the effect of a reinforcer in Stimulus Presentation $S_{1}$ is related to the conditions under which reinforcement is available in Stimulus Situation $\mathbf{S}_{2}$ (Catania, 1969; Rachlin \& Baum 1969; Walker, Schnelle, \& Hurwitz, 1970).

The increase in relaxation as a function of the TO period and the assumption that sensitivity to shock is heightened as a function of the duration of TO allows us to make two predictions, both of which appear to be supported by the present results. The first prediction is that the rate of response during TO would be a decreasing function of the TO period, on the grounds that relaxation introduced by the TO stimulus interferes with the behavior conditioned to the TI stimuli; secondly, the probability of receiving the first shock after the beginning of each TI period increases as the TO period preceding a $\mathrm{TI}$ is lengthened. The prediction is based on the idea that the longer the TO, the more relaxed the $S$ and the greater the time required to arouse a level of anxiety which would result in avoidance behavior.

Since we have already stated that the effectiveness of the first shock increases as TO increases, the observed increase in the rate of response as TO increased from $16 \mathrm{sec}$ to $2 \mathrm{~min}$ was predictable. One would expect a limit to this function, i.e., that beyond a given duration of $\mathrm{TO}$, no additional increases in the rate of response are likely to occur which would be attributable to the S's heightened sensitivity to shock. There are various indications in the literature, including the results of the present experiment, that the limit lies between 1 and 2 min for rats (e.g., Brush, 1962).

$$
\text { REFERENCES }
$$

BRUSH, F. R. The effects of intertrial interval on avoidance learning in the rat. Joumal of Comparative \& Physiological Psychology, 1962, 55, 899-992.

CATANIA, A. C. Concurrent performances:

Inhibition of one response by reinforcement of another. Journal of the Experimental Analysis of Behavior. 1969 12.731-740.

DENNY, M. R. Relaxation theory and experiments. In F. R. Brush (Ed.), Aversive conditioning and learning. New York: Academic Press, 1971 , in press.

HOFFMAN, H. S., FLESCHLER, M., \& CHORNY, H. Discriminated bar press avoidance. Journal of the Experimental Analysis of Behavior, 1961, 4, 309-316. HOFFMAN, H. S., \& FLESCHLER, M. The course of emotionality in the development of avoidance. Journal of Experimental Psychology, 1962, 64, 288-294.

HOFFMAN, H. S. The stimulus generalization of conditioned suppression. In D. Mostofsky (Ed.). Stimulus generalization. Stanford, Calif: Stanford University Press, 1965. Pp. 35 6-372.

KAMIN, L. J. The effects of termination of the $C S$ and avoidance of the US on avoidance learning. Journal of
Comparative \& Physiological Psychology, $1956,49,420-424$.

MOWRER, $O$. H. A stimulus-response analysis of anxiety and its role as a reinforcing agent. Psychological Review, $1939,46,553-565$.

NAKAMURA, C. Y., \& ANDERSON, N Avoidance behavior differences within and between strains of rats. Journal of Comparative \& Physiological Psychology. 1962, 55, 740-747.

RACHLIN, H., \& BAUM, M. Response rate as a function of amount of reinforcement for a signalled concurrent response. Journal of the Experimental Analysis of Behavior, 1969, 12, 11-16.

WALKER, S. F., SCHNELLE, J, F., \& HURWITZ, H, M, B. Rates of concurrent responses and reinforcer duration. Psychonomic Science, 1970, 21, 173-175. WERTHEIM, G. A. Some sequential aspects of IRT's emitted during Sidman avoidance behavior in the white rat. Journal of the Experimental Analysis of Behavior, 1965, 8, 9-15.

\title{
Effect of repeated shock presentations and different stimulus intensities on shock-induced aggression
}

\author{
THOMAS L. CREER, CARIH, Denver, Colo. 80204 \\ and \\ D. A. POWELL, V.A. Hospital, Columbia, S.C. 29208
}

This study demonstrated that shock of various intensities induced similar fighting frequencies when rats were paired together for several sessions. A general increase in rates of fighting over sessions was also indicated with four of the stimulus intensities employed in the investigation.

Ulrich \& Azrin (1962) reported that the optimal shock intensity for inducing high rates of fighting was $2 \mathrm{~mA}$. Lower intensities of shock were considered to lack the appropriate aversiveness, while the higher intensities generated competing or debilitating behaviors. Similar findings with regard to the intensity of shock were later shown by Dreyer \& Church 